\title{
DEVELOPING CHEMICAL ENGINEERING ACUMEN by Brewing Kicking Mule Beer
}

\author{
Matthew J. Armstrong, Joshua P. White, Jesse W. Hudgins, Geoffrey R. Bull, Corey M. James, Dawn \\ E. Riegner, April D. Miller, Andrew Biaglow \\ United States Military Academy • West Point, NY 10996
}

$\mathrm{B}$ atch quantity beer production at West Point serves a number of audiences: the American Institute of Chemical Engineering (AIChE) Student Chapter, cadets and faculty, and the chemical engineering curriculum. This is optional for Chemical Engineering cadets and is open to any interested cadet. Beer making is a nearly ideal process to demonstrate a wide variety of chemical engineering concepts and has recently served this purpose at several other undergraduate institutions. ${ }^{[1-6]}$ Heat transfer, reactor design and kinetics, process control, separations, and basic unit operations are all included in one process, and the data analysis has the potential to tie into our Chemical Engineering electives in our eight semester academic sequence. ${ }^{[7-11]}$ We will articulate this potential in the Discussion section.

The process begins with the creation of wort, which is the sugary precursor to beer. Wort contains the sugars necessary for fermentation in addition to hops for flavor, bitterness, and aroma. In our process, cadets create the wort from milled grain by cooking the grain in an aqueous batch reactor (also known as the "mash tun" in the vernacular of beer brewing). The heat of cooking activates enzymes that break down long-chain sugars into short-chain, fermentable, sugars. This process exposes cadets to concepts taught in Separation Processes classes, such as solid-liquid extraction and leaching. ${ }^{[6,11]}$

When yeast is added following the production of the wort (the mash with the grain solids removed), cadets also get an introduction to the overlap of chemical and bioengineering. Because the yeast cells are alive, undergoing their lifecycle from cell birth to cell growth and cell apoptosis, this batch system, in addition to brewing the beer, is also a bioreactor. The sugar and temperature must be controlled under a range that would optimize the yeast life cycle and produce ethanol. ${ }^{[5,6]}$ Maintaining and engineering adequate conditions for the life cycle of the yeast cells has clear ties to biological engineering.

Temperature control is important throughout the beer
LTC Matthew Armstrong has been teaching Chemical Engineering and Chemistry at the United States Military Academy for 6 years. He is the Program Director, and Course Director for Chemical Engineering $L a b$ and Chemical Engineering Professional Practice. He received his B.S. and M.S. from Rensselaer Polytechnic Institute and Ph.D. in Chemical Engineering from University of Delaware. He serves as the Head Officer Representative of the Chemical Engineering Club.

LTC Geoffrey Bull has been teaching Chemical Engineering, Chemistry and/or Physics at the United States Military Academy for 7 years. He served as the Chemical Engineering Program Director for 3 years and was Course Director for Heat and Mass Transfer and Chemical Reactor Design. He received his B.S. from United States Military Academy and M.S. and Ph.D. in Nuclear Engineering and Engineering Physics from University of Wisconsin-Madison.

CPT Joshua White taught Chemistry at the United States Military Academy for two years and was the Chemical Engineering Club Head Brewmaster. He has a B.S. in Chemical Engineering from the United States Military Academy and M.S. in Chemical Engineering from the University of South Carolina.

LTC Corey James has been teaching Chemical Engineering and Chemistry at the United States Military Academy for 4 years. He is an Academy Professor, Assistant Program Director, and Course Director for Introduction to Automatic Process Controls. He received a B.S. in Chemistry and Life Science from the United States Military Academy and an M.S. and Ph.D. in Chemical Engineering from University of Texas, Austin.

Dr. Dawn Riegner is an Associate Professor and has been teaching Chemistry at the United States Military Academy for 20 years. She has a B.S. in Chemistry from University of North Carolina, and a Ph.D. in Chemistry from University of Texas, Austin.

LTC April Miller is an Assistant Professor and has been teaching Chemistry and Chemical Engineering at the United States Military Academy for 2 years. She has a B.S. in Chemical Engineering from Clarkson University, an M.S. in Nuclear Engineering from the Air Force Institute of Technology and Ph.D. in Chemical Engineering from the University of Nebraska-Lincoln. She is an Officer Representative for the Chemical Engineering Club.

Dr. Andrew Biaglow is a Professor of Chemical Engineering and has been teaching Chemistry and Chemical Engineering at the United States Military Academy for 25 years. He has a B.S. in Chemical Engineering from Case Western and Ph.D. in Chemical Engineering from the University of Pennsylvania.

Cadet Jesse Hudgins is a Firstie (Senior) enrolled in the Chemical Engineering Program at the United States Military Academy. He is actively involved in undergraduate research as the Cadet Brewmaster in the Chemical Engineering Club.

(1) Copyright ChE Division of ASEE 2019 
brewing process. During wort production, the temperature at which the enzymes are activated will produce longer- or shorter-chain sugars leading to more- or less-fermentable sugars. By controlling the temperature throughout the fermentation process, students have the opportunity to collect kinetic reaction data. They collect this data using a refractometer, hydrometer, and gas chromatograph with mass spectrometric detection (GCMS). After collecting data from several fermentations (at least three), they can model the data using the Parallel Tempering Algorithm, which is a recently published global, stochastic data fitting optimization algorithm with several appropriate bio-kinetic models used for the production of ethanol. ${ }^{[6,12,13]}$ While accounting for the variables of sugar consumption rates, ethanol production rates, and biomass content, cadets fit their experimental data to models from literature, which includes the Monod, Aiba, Tiessier and Hinshelwood models. ${ }^{[13-17]}$ By modeling the data, students observe how the temperature of the fermenter affects the reaction rate. A higher fermenter temperature yields a faster, more vigorous fermentation reaction rate.

Our beer brewing process uses a countercurrent plate heat exchanger to chill the wort from boiling to a temperature suitable for fermentation in a single pass of tap water. By adjusting the wort flow rates with a pump, and the countercurrent cold water with a faucet, students can achieve the optimal flow rates and temperatures to chill the wort for fermentation. Cadets use this information to calculate the heat transfer parameters for the heat exchanger. After seeing the application of the heat exchanger, cadets model the process in CHEMCAD using a countercurrent heat exchanger unit to develop their capabilities with the software and to gain confidence in performing an energy balance on a practical, working, system. ${ }^{[8,10]}$

The remainder of the paper is as follows: we will demonstrate how the Kicking Mule Beer brewing process incorporates chemical engineering aspects and facilitates development of acumen in chemical reaction engineering, data fitting and optimization, lab data analysis, and process controls. We first show the collected reactant and product vs. time data for three batches of Kicking Mule beer and fit the data to published bio-kinetic models. We fit the model parameters to the data using a recently published optimization algorithm. We then show how we calculate the overall heat transfer coefficients for all of our heating and cooling equipment using best practices outlined in literature. Following this effort, we record transient temperature control information on our PID temperature controlling device. Finally, with our modeling and parametric analysis complete, we use the CHEMCAD software to model parts of the process. Each of these subtopics is a course, or a part of one of our courses; readers can see a list of all required courses at https://www.
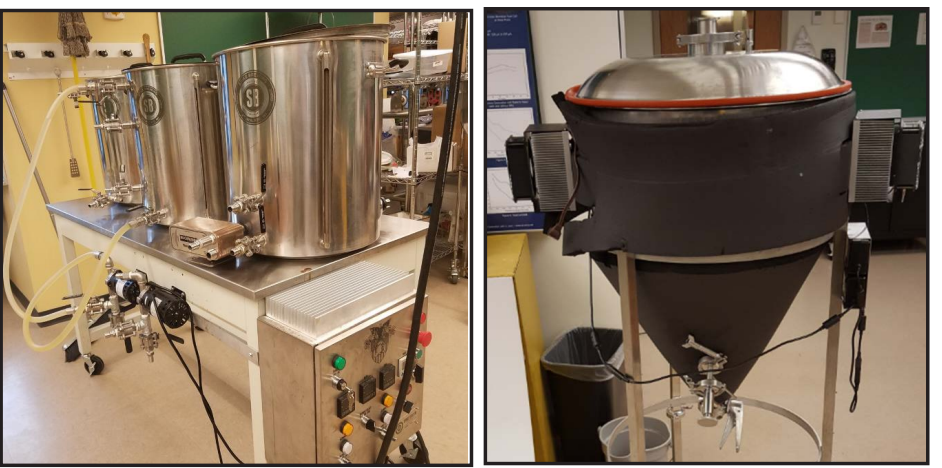

$b$

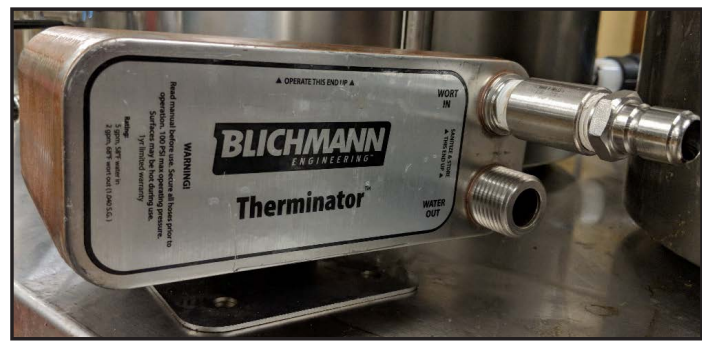

Figure 1. Brewing apparatus: a. E-HERMS.; b. Fermentation reactor; c. Blichmann Heat Exchanger.

usma.edu/chemistry/SitePages/Chemical\%20Engineering. aspx.

\section{APPARATUS AND METHODS}

The beer brewing system used by cadets in our program is a professional, three-vessel, electric system used to brew beer from grain. This system gives industry-level precision for temperatures and controls. The system is an Electric Heat Exchange Recirculating Mash System (E-HERMS) and allows for multiple levels of control throughout the brewing process from the mash to the boil and then to the fermenter which is also temperature controlled, and therefore the control aspect of this process can also be modeling in the context of our Chemical Engineering Process Controls course. ${ }^{[9]}$

The beginning of the brewing process starts with recipe selection, to include types and roasts of grains, types and amounts of hops, and strain of yeast for fermentation. Once the recipe is finalized, the grain is milled to expose the starches and subsequently maximize the contact time of the starches with the water. The process of cooking the starches out of the grain to produce the "mash" occurs in the far-left vessel of the E-HERMS shown in Figure 1a.

To activate the desired enzymes when the milled grain is mixed with heated water, the temperature must be precisely regulated. The mash needs to be held at a constant temperature for about an hour, and our system uses a constant recirculation of the mash through a coiled heat exchanger which is immersed in a water bath in the middle tank, called the 
hot liquor tank (HLT). The constant recirculation is achieved through a gravity primed liquid pump and high temperature hoses. The water in the hot liquor tank is heated and the temperature regulated through a Proportional-Integral-Derivative (PID) controller and an electric heating element. The main control panel allows for exact PID control of the temperature in the HLT which in turn transfers heat to the mash through the heat exchanger. This allows for indirect heating of the mash during starch conversion which mitigates any scorched grains and off flavors from direct fired heating. The constant recirculation also allows for the water in the mash to be drawn through the grain bed, which settles, and acts as a filter giving a clearer product. This portion of the process allows for hands-on application of controls as well as unit operations.

Once the mash has finished its conversion, which is monitored with a refractometer to ensure completion, the fully converted sugar solution, called wort, is pumped to the far-right vessel, shown in Figure 1a, the boil kettle. This demonstrates real world plant-type operations in determining which valves need to be closed, which hoses need to be moved, and which pumps need to be running.

When the wort is completely transferred, it is boiled. The boil kettle also uses an electric heating element to provide energy. The element uses a separate controller to regulate output from $0-100 \%$ power. This gives cadets another step to control and minimize energy use while still maintaining a rolling boil. During the boil, hops are added. By regulating the amount, variety, and time at which the hops are added during the boil, cadets can affect the characteristics of the final product. Specifically, by varying the boil time, the alpha acids in the hops contribute to a spectrum of characteristics, including aroma, flavor, and bitterness. At the conclusion of the boil, the wort needs to be cooled rapidly in order to reach a temperature conducive to yeast fermentation.

Post-boil processing is critical for the wort, as the transition from the boil kettle to the sanitized fermenter exposes the product to potential infection from airborne bacteria or wild yeast. Cooling rapidly with minimum contact time to the atmosphere reduces the chance for contamination as well as minimizing process time. In order to accomplish this, we use a counter-current plate heat exchanger shown in Figure 1c. The wort is sent through the sanitized heat exchanger, with regular tap water run counter-currently. By regulating the flow rates of both the wort and the tap water, cadets can achieve the desired temperature, usually about $68^{\circ} \mathrm{F}$, maximize flow rate of the wort, and minimize exposure to bacteria. After the wort is cooled, it is moved to the unagitated fermenter shown in Figure 1b. The fermenter is equipped with both a heating pad and Peltier coolers in order to regulate the temperature during fermentation. The fermenter also has a side valve to take samples during fermentation. The cadets track fermentation using multiple analytical methods.

Three main methods are used to track ethanol production, as well as sugar consumption, over time. The first method employs an industry standard hydrometer. The density of the wort changes as sugar is converted to ethanol, changing the level the hydrometer floats. We also used a refractometer which uses the refractive index of the wort solution to track sugar content. This method is not as widely used, as the addition of ethanol, as well as biomass, in the solution, skews the refraction. While it is possible to compensate, the refraction method is not as accurate for active fermentation and, because of the large uncertainty associated with it, we did not include this data in our analysis. However, the uncertainty in this data could be improved in future runs by using a centrifuge to remove the biomass and yeast from the sample, giving a clearer solution for the refraction measurement. This data could then be more useful for comparison to the other methods.

The final method we use is GC-MS, specifically, a polar Supelcowax capillary column $(30 \mathrm{~m} \times 0.2 \mathrm{~mm} \times 0.2 \mu \mathrm{m})$. We used the internal standard calibration method with methanol as the internal standard. We used an oven temperature program of: $1 \mathrm{~min}$ at $40^{\circ} \mathrm{C}$, ramp to $240^{\circ} \mathrm{C}$ at $100^{\circ} \mathrm{C}$ per min, and then holding at $240^{\circ} \mathrm{C}$ for 30 seconds. Samples were filtered using $0.2 \mu \mathrm{m}$ filters before adding the internal standard. This allows a very precise measurement of alcohol production over time, incorporating our chemistry majors by bringing a new and practical project into their laboratory experience. These methods are then compared to see if they correlate, while also providing multiple data sets to use for kinetic modeling. An example of the consistency and corroboration of the hydrometer reading and GC-MS is shown in the results section.

\section{SAFETY}

The brewing process pedagogical method provides the perfect opportunity to discuss process safety and demonstrate the need to imbed safety in the design process. Safety concerns include burning hazards, electrical hazards, and the typical "slips, trips and falls" risk that is ubiquitous in all chemical engineering plant operations. Cadet leadership was directed to ensure safety best practices were followed. A formal written risk assessment is briefed prior to operations and safety measures are enforced throughout the process, as per the $\mathrm{Ca}$ dets Safety and Chemical Engineering Education (SAChE) training <https://www.aiche.org/ccps/community/technological-communities/safety-and-chemical-engineering-education-sache/certificate-program $>$, that all of the senior Cadets must take in conjunction with their Senior Chemical Engineering Lab Course.

\section{DATA ANALYSIS}

\section{Yeast Fermentation Kinetics Analysis}

Brewing beer is a bioprocess in which the consumption of sugar by living yeast cells produces two products: the desired product, ethanol, and undesired biomass. From a reaction ki- 
netics perspective, this is not a convenient first-, second-, or even fractional-order reaction with which our students are generally familiar. Determining an appropriate model (rate law) which they can then apply to their knowledge of reactor design is a critical skill. This methodology also provides background for discussions about whether achieving models that follow from first principles is necessary or desired, or if the data takes precedent when designing or scaling systems.

For the kinetic reaction data presented in this paper, three modeling equations were used. The model representing the production of biomass given by Eq. 1 below, where all concentrations are mass-based:

$$
\text { Biomass : } \frac{\mathrm{dX}}{\mathrm{dt}}=\mu(\mathrm{t}) \mathrm{X}(\mathrm{t})
$$

where $X$ is the concentration of cells and $\mu(t)$ is the specific growth or kinetic reaction rate with respect to time. The production of the desired product, ethanol, follows a similar model given by Eq. 2 :

$$
\text { Ethanol: } \frac{\mathrm{dP}}{\mathrm{dt}}=q(\mathrm{t}) \mathrm{X}(\mathrm{t})
$$

where $P$ is the ethanol concentration, and $q(t)$ is the product accumulation rate. The ethanol production model shows a rate of increase of product concentration $P$ with respect to time given cell concentration $X$ and kinetic rate of reaction $q(t)$. These models are reliant on the consumption of the substrate sugar. The rate of consumption of sugar is given by equation Eq. 3:

$$
\text { Sugar }: \frac{\mathrm{dS}}{\mathrm{dt}}=-\frac{1}{\mathrm{Y}_{\mathrm{x} / \mathrm{s}}} \frac{\mathrm{dX}}{\mathrm{dt}}-\frac{1}{\mathrm{Y}_{\mathrm{p} / \mathrm{s}}} \frac{\mathrm{dP}}{\mathrm{dt}}
$$

where $\mathrm{S}$ is the concentration of the sugar, and $\mathrm{Y}_{\mathrm{x} / \mathrm{s}}$ and $\mathrm{Y}_{\mathrm{p} / \mathrm{s}}$ are the yield coefficients. ${ }^{[13-17]}$. The rate of consumption of substrate $S$ is in proportion with the rates of production of both the cell concentration $X$ and the product concentration $P$. The ratio of both products produced from the consumed substrate is represented by the yield coefficients $\mathrm{Y}_{\mathrm{x} / \mathrm{s}}$ and $\mathrm{Y}_{\mathrm{p} / \mathrm{s}}{ }^{[13-17]}$

The following models from literature depict the fermentation process over time. In each model, $\mu(t)$ represents the specific growth rate and $q(t)$ represents the specific product accumulation rate. The function $S(t)$ is the concentration of substrate over time and is a term in each of the four kinetic models we model with the ethanol data presented here. The Aiba and Hinshelwood models include the function $P(t)$ representing the concentration of the product ethanol over time. ${ }^{[13-17]}$ As shown in Eqs. 4-7, each of the four models have unique expressions for the specific growth rate $\mu(t)$ and the specific product accumulation rate $q(t)$. Table 1 has a listing and description of each of the respective model parameters.
MONOD:

$$
\begin{aligned}
& \mu=\mu_{\max }\left(\frac{S(t)}{K_{s x}+S(t)}\right) \\
& q=q_{\max }\left(\frac{S(t)}{K_{s p}+S(t)}\right)
\end{aligned}
$$

TESSIER:

$$
\begin{aligned}
& \mu=\mu_{\max }\left(1-\exp \left\{-\frac{\mathrm{S}(\mathrm{t})}{\mathrm{K}_{\mathrm{sx}}}\right\}\right) \\
& \mathrm{q}=\mathrm{q}_{\max }\left(1-\exp \left\{-\frac{\mathrm{S}(\mathrm{t})}{\mathrm{K}_{\mathrm{sp}}}\right\}\right)
\end{aligned}
$$

AIBA:

$$
\begin{aligned}
& \mu=\mu_{\max }\left(\frac{\mathrm{S}(\mathrm{t})}{\mathrm{K}_{\mathrm{sx}}+\mathrm{S}(\mathrm{t})}\right) \exp \left\{-\mathrm{K}_{\mathrm{ix}} \mathrm{P}(\mathrm{t})\right\} \\
& \mathrm{q}=\mathrm{q}_{\max }\left(\frac{\mathrm{S}(\mathrm{t})}{\mathrm{K}_{\mathrm{sp}}+\mathrm{S}(\mathrm{t})}\right) \exp \left\{-\mathrm{K}_{\mathrm{ip}} \mathrm{P}(\mathrm{t})\right\}
\end{aligned}
$$

\begin{tabular}{|c|c|c|c|}
\hline Model & Parameter & Units & Description \\
\hline \multirow{6}{*}{$\begin{array}{c}\text { Monod \& } \\
\text { Tessier }\end{array}$} & $\mu_{\max }$ & days $^{-1}\left(d^{-1}\right)$ & model parameter \\
\hline & $\mathrm{K}_{\mathrm{sx}}$ & $\mathrm{g} \mathrm{dm}^{-3}$ & model parameter \\
\hline & $\mathrm{q}_{\max }$ & $\mathrm{g}(\mathrm{g} \mathrm{d})^{-1}$ & model parameter \\
\hline & $\mathrm{K}_{\mathrm{sp}}$ & $\mathrm{g} \mathrm{dm}^{-3}$ & model parameter \\
\hline & $\mathrm{Y}_{\mathrm{x} / \mathrm{s}}$ & - & yield coefficient \\
\hline & $Y_{p / s}$ & - & yield coefficient \\
\hline \multirow{8}{*}{$\begin{array}{c}\text { Aiba \& } \\
\text { Hinshelwood }\end{array}$} & $\mu_{\max }$ & days $^{-1}\left(d^{-1}\right)$ & model parameter \\
\hline & $\mathrm{K}_{\mathrm{sx}}$ & $\mathrm{g} \mathrm{dm}^{-3}$ & model parameter \\
\hline & $\mathrm{q}_{\max }$ & $\mathrm{g}(\mathrm{g} \mathrm{d})^{-1}$ & model parameter \\
\hline & $\mathrm{K}_{\mathrm{sp}}$ & $\mathrm{g} \mathrm{dm}^{-3}$ & model parameter \\
\hline & $\mathrm{Y}_{\mathrm{x} / \mathrm{s}}$ & - & yield coefficient \\
\hline & $\mathrm{Y}_{\mathrm{p} / \mathrm{s}}$ & - & yield coefficient \\
\hline & $\mathrm{K}_{\mathrm{ix}}$ & $\mathrm{g} \mathrm{dm}^{-3}$ & model parameter \\
\hline & $\mathrm{K}_{\mathrm{ip}}$ & $\mathrm{g} \mathrm{dm}^{-3}$ & model parameter \\
\hline
\end{tabular}

\section{HINSHELWOOD:}

$$
\begin{aligned}
& \mu=\mu_{\max }\left(\frac{S(t)}{K_{s x}+S(t)}\right)\left(1-K_{i x} P(t)\right) \\
& q=q_{\max }\left(\frac{S(t)}{K_{s p}+S(t)}\right)\left(1-K_{i p} P(t)\right)
\end{aligned}
$$

TABLE 1

Model Parameters, Units and Descriptions ${ }^{[13-17]}$

Chemical Engineering Education 


\section{MODEL FITTING PROCEDURE}

The data are collected for each of the three runs via a hydrometer, and the current density is correlated with a sugar and ethanol concentration. At the beginning of the reaction there is a lag of approximately 24-36 hours and then a quick ramp up in ethanol production and sugar consumption. Therefore, we frontload a greater frequency of data collection for the first 3-4 days of the reaction, with 3-4 readings per 24-hour period. We record data for approximately 8- 10 days, taking $2-3$ readings per 24 -hour period.

However, empirical data for the biomass cell count needed for the models could not be collected, and so there was no yeast concentration vs time data to incorporate into the ODEs. Future iterations, however, will have the advantage of including measured yeast concentration values, courtesy of an automated yeast cell counter procured after these data were taken. With the data we did collect, we executed a stochastic minimization, parallel tempering-like, algorithm ${ }^{\text {[12] }}$ for each of the data sets of sugar and ethanol and allowed the stochastic models to find the "best fit parameters" for each of the kinetic models, including the kinetic parameter for yeast. Each of the kinetic models was fit with the stochastic algorithm a total of five times with randomized initial guess, and the parameter values yielding the smallest $\mathrm{F}_{\text {cost }}$ were recorded, as well as the average and standard deviation from each of the 5 fits for each of the models, for each of the three data sets. Because the minimization algorithm is stochastic and global, there is a different value for each of the "best-fit" parameter values on each of the runs, with a different value of cost function, shown in Eq. 8. In addition, we calculate a residual sum of squares (RSS) value for each run, shown in Eq. 9. ${ }^{[12]}$ Lastly we incorporate an Akaike Information Criteria (AIC), shown in Eq. 10, for each best model fit, which attempts to "level the playing field by assigning a penalty for over-fitting data sets, whereby models with more parameters are penalized more than lower parameter counterparts. ${ }^{[18]}$

For the parallel tempering algorithm, we run $\mathrm{N}_{\text {run }}$ number of separate, yet parallel runs, whereby new parameters are guesses based on a search algorithm. Each of the runs is at a different "Boltzman Energy" $\left(\mathrm{E}_{\mathrm{B}}\right)$, in such a way that there is a larger parameter space explored the higher the $E_{B}$, and higher probability of keeping a set of parameters that produce a larger value of $\mathrm{F}_{\text {cost }}$. Lastly, the algorithm pauses at prearranged times to compare parameter values with neighbor runs to the left and right. Parameter sets yielding low $\mathrm{F}_{\text {cost }}$ values are slowly shifted to the "cold" side over time, thereby producing the best fit set of parameters. We run each fit for each data set and each respective model five times. We chose to run each model for each data set five times to give us a large enough population of fit model parameters to enable the calculation of average and standard deviation for each parameter fit. By using a stochastic fitting algorithm, gathering and reporting statistics allows a deeper under- standing of the kinetic models and the dynamic process, and also allows reporting each parameter average and standard deviation shown in Tables $2 \mathrm{a}-\mathrm{c} .^{[12-17]}$

There are N ${ }^{\text {run }}$ number of "Energy Levels", whereby new parameters are guessed. If the new set of parameters produces a better cost function value, they are kept; however, there is a probability $\left(\mathrm{P}_{\mathrm{A}}\right)$ of acceptance even when there is no improvement based on cost function value. Over the course of the algorithm running, "nearest neighbor" energy levels compare parameter and cost function values, and exchange parameters sending the best parameter values based on cost function to the colder end of the flow chart. The cost function is computed as follows ${ }^{[12]}$ :

$$
\mathrm{F}_{\text {cost }}=\sum_{\mathrm{i}}^{\mathrm{N}}\left(\sqrt{\left(\mathrm{f}_{\mathrm{EIOH}, \mathrm{i}}-\mathrm{y}_{\mathrm{EIOH}, \mathrm{i}}\right)^{2}+\left(\mathrm{f}_{\mathrm{GLUC} \mathrm{i}}-\mathrm{y}_{\mathrm{GLC}, \mathrm{i}}\right)^{2}}\right) / 2
$$

where $f_{i}$ is the model prediction of concentration and $y_{i}$ is the actual concentration. The residual sum of squares is shown below, and is another useful metric required for the AIC calculation:

$\operatorname{Mod} . \operatorname{RSS}=\sum_{\mathrm{i}}^{\mathrm{N}}\left(\sqrt{\left(\mathrm{f}_{\mathrm{ErOH}, \mathrm{i}}-\mathrm{y}_{\mathrm{ErOH}, \mathrm{i}}\right)^{2}+\left(\mathrm{f}_{\mathrm{GLUC}, \mathrm{i}}-\mathrm{y}_{\mathrm{GLUC}, \mathrm{i}}\right)^{2}}\right) / 2 N$

Lastly the AIC is calculated per Eq. 10,

$$
\mathrm{AIC}=2 \mathrm{k}+2 \ln (\text { Mod.RSS })
$$

where $\mathrm{k}$ is the number of model parameters, and RSS is the residual sum of squares. ${ }^{[12]}$

\section{MODEL FITTING RESULTS}

The four model fitting results are shown below in Figures $2 \mathrm{a}-\mathrm{c}$. The additional two parameters utilized by the Aiba and Hinshelwood models give slightly better fits for modeling the ethanol production and glucose consumption vs time, as demonstrated by the lower cost functions. However, there were several time gaps in data collection, amounting to 1-3 days, that, when filled in future iterations of this process, could impact which model provides the most appropriate fit. These data gaps also demonstrate the criticality of planning the entire timeline of experiments to be able to collect complete sets of data.

The values of the best fit parameters for the Monod, Tessier, Aiba, and Hinshelwood models, for each of the data sets along with averages, $\mu$, and standard deviations, $\sigma$, are shown in Table 2a-d below. ${ }^{[13-17]}$

The overall model comparisons for each data set are shown in Table 3 for each of the respective ethanol and glucose data sets from May 2017, July 2017 and October 2017. In this case, having more parameters improves the modeling of the sugar and ethanol concentrations, per the decreased cost function numbers. This, however, comes with a penalty 
as shown by the respective increased AIC values. This is a critical lesson on modeling and optimization for the cadets. In this case, the addition of two model parameters is potentially justified because of the better fit (cost function); however, this will not necessarily be true for all models. As seen in Table 3, the parameter penalty does not significantly change the comparison. ${ }^{[13-17]}$ The best models are then carried forward for use in our Chemical Reactor Design course to model batch reactors. With the kinetic models above, and best fit parameters, one can modify the kinetic equations in CHEMCAD with excel Macros and model the batch reactor, obtaining the correct reactor volume that will agree with the actual fermentation reactor volume.

Not incorporated into this set of data and analysis is a detailed discussion of uncertainty in both the data collection and model fitting. While the measured data was estimated to have uncertainty of approximately $\pm 10 \%$, the critical discussion of comparing different models that may all lie within the uncertainty of the measurements was outside the scope of the initial model fitting exercise described here. Future iterations of both data collection and model analysis will include appropriate discussion of measurement and model parameter error.

To validate our data collection activities using the hydrometer, which was the basis of the kinetic model fitting optimization, we compare the GC-MS and hydrometer data for the ethanol concentration in Table 4. As seen, the two methods agree to within $10 \%$.

\section{CONTROLS DATA ANALYSIS}

Students observe the advantage of process control in the brewing process, which is incorporated into many facets of engineering, and is directly applicable to the Introduction to Automatic Process Controls course. Seemingly abstract material taught in the classroom is reinforced in a fun and interesting manner. Observing a system that uses process control for safety and product specifications physically demonstrates the importance of accurate system modeling, controller design, tuning, and sensor and valve selection, while highlighting the balance between performance and robustness.

In brewing, the temperature is the most important controlled variable $(\mathrm{CV})$ because it ultimately affects taste and alcohol content. Through their brewing, students first briefly witness the system with no control. PID control is then used to demonstrate the ability of the engineer to control product quality with automated CV manipulation. ${ }^{[9]}$

One of the many advantages of a PID controlled process shown in Figure 3 is the ability to demonstrate the effects of changing controller parameters. This can be done in the controller, but it is easier, less expensive, and just as effective to do on a simulation of the actual process. Once students successfully model either the wort tank or the fermenter, control
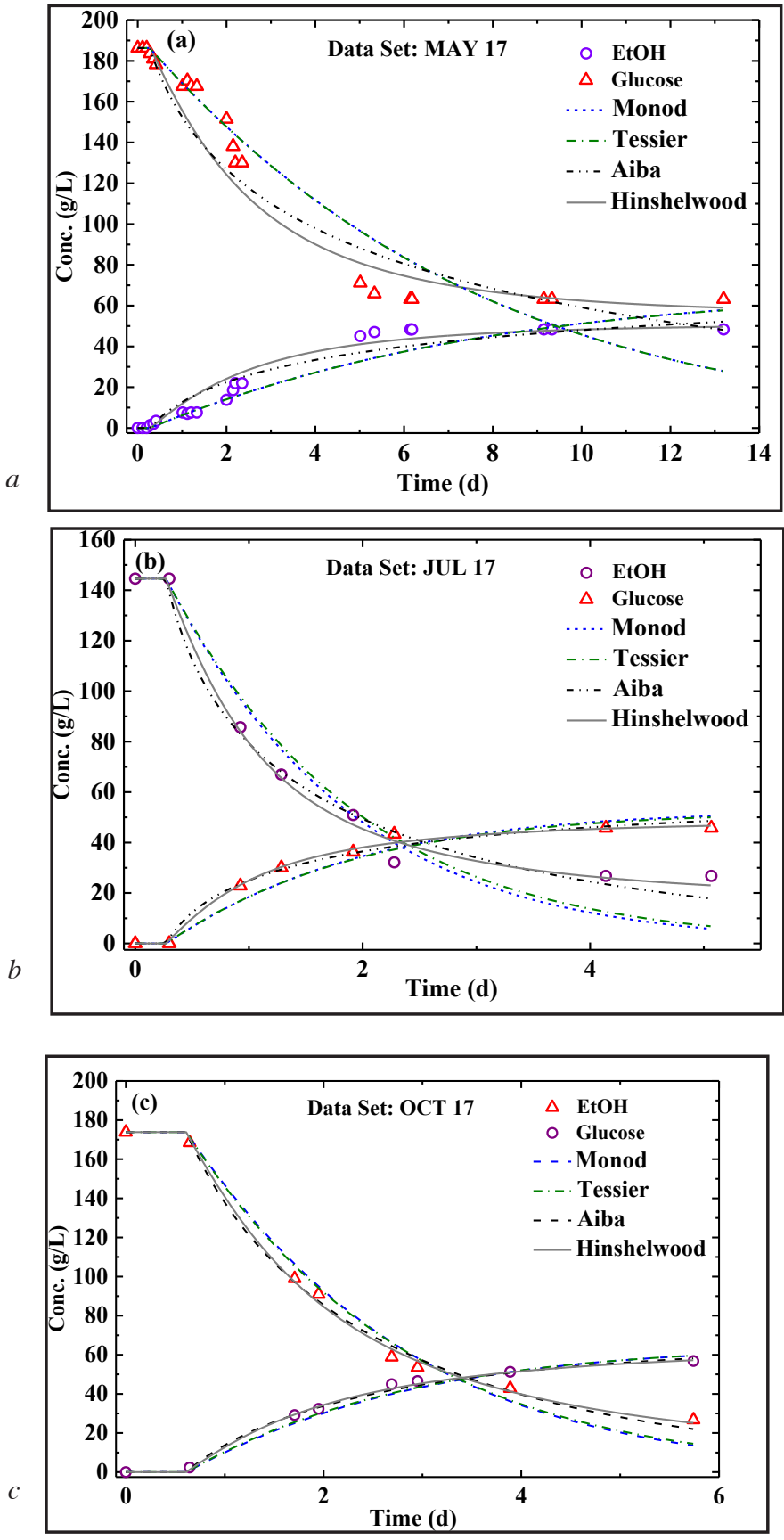

Figure 2a: Ethanol and glucose vs. time kinetic data of the Kicking Mule Brewery run from May 2017; b. July 2017; c. October 2017. Depicted are the model fits using the Monod, Tessier, Aiba, and Hinshelwood kinetic models.

algorithms are applied to the modeled process. ${ }^{[9]}$

A tremendous learning opportunity is presented for cadets in the applying of various control laws (P, PI, PID) on the same process, while also demonstrating the importance of accurate tuning and establishing key parameters, such as gain and time constants. Cadets' classroom instruction is 
TABLE 2a

Best fit Monod model parameters for May 2017, July 2017, and October 2017, with averages $(\mu)$ and standard deviations $(\sigma)$.

\begin{tabular}{|r|c|c|c|c|c|c|c|c|c|c|}
\hline & \multicolumn{3}{|c|}{ May-17 } & \multicolumn{3}{|c|}{ Jul-17 } & \multicolumn{3}{|c|}{ Oct-17 } & \\
\hline Parameter & Best & $\boldsymbol{\mu}$ & $\boldsymbol{\sigma}$ & $\mathbf{B e s t}$ & $\boldsymbol{\mu}$ & $\boldsymbol{\sigma}$ & $\mathbf{B e s t}$ & $\boldsymbol{\mu}$ & $\boldsymbol{\sigma}$ & units \\
\hline $\boldsymbol{\mu}_{\max }$ & $\mathbf{0 . 3 0}$ & 0.32 & 0.03 & $\mathbf{0 . 6 6}$ & 0.27 & 0.12 & $\mathbf{0 . 4 4 6}$ & 0.426 & 0.012 & $\mathbf{d}^{-1}$ \\
\hline $\mathbf{K}_{\mathbf{s x}}$ & $\mathbf{3 7 2 0}$ & 2200 & 990 & $\mathbf{9 2 0 0}$ & 9100 & 400 & $\mathbf{8 7 1 0}$ & 9390 & 650 & $\mathbf{g ~ d m}^{-3}$ \\
\hline $\mathbf{K}_{\mathbf{s p}}$ & $\mathbf{6 4 0}$ & 320 & 280 & $\mathbf{5 4 5}$ & 533 & 53 & $\mathbf{6 7 5}$ & 634 & 34 & $\mathbf{g ~ ( g ~ d ) ~}^{-1}$ \\
\hline $\mathbf{q}_{\mathbf{p m a x}}$ & $\mathbf{1 0 9 0}$ & 610 & 410 & $\mathbf{4 2 0 0}$ & 4200 & 320 & $\mathbf{4 0 7 0}$ & 3860 & 180 & $\mathbf{g ~ d m}^{-3}$ \\
\hline $\mathbf{Y}_{\mathbf{x} / \mathbf{s}}$ & $\mathbf{0 . 8 8}$ & 0.44 & 0.56 & $\mathbf{5 . 3 E - 0 6}$ & 0.013 & 0.027 & $\mathbf{0 . 6 1}$ & 0.80 & 0.22 & - \\
\hline $\mathbf{Y}_{\mathrm{p} / \mathbf{s}}$ & $\mathbf{0 . 4}$ & 4.2 & 3.1 & $\mathbf{0 . 6 6}$ & 0.54 & 0.11 & $\mathbf{0 . 3 7 2}$ & 0.373 & 0.001 & - \\
\hline \hline
\end{tabular}

TABLE 2b

Best fit Tessier model parameters for May 2017, July 2017, and October 2017, with averages $(\mu)$ and standard deviations $(\sigma)$.

\begin{tabular}{|r|c|c|c|c|c|c|c|c|c|l|}
\hline & \multicolumn{3}{|c|}{ May-17 } & \multicolumn{3}{|c|}{ Jul-17 } & \multicolumn{3}{|c|}{ Oct-17 } & \\
\hline Parameter & Best & $\boldsymbol{\mu}$ & $\boldsymbol{\sigma}$ & Best & $\boldsymbol{\mu}$ & $\boldsymbol{\sigma}$ & $\mathbf{B e s t}$ & $\boldsymbol{\mu}$ & $\boldsymbol{\sigma}$ & units \\
\hline $\boldsymbol{\mu}_{\max }$ & $\mathbf{0 . 3 1}$ & 0.32 & 0.01 & $\mathbf{0 . 3 7}$ & 0.43 & 0.02 & $\mathbf{0 . 4 3}$ & 0.42 & 0.02 & $\mathbf{d}^{-1}$ \\
\hline $\mathbf{K}_{\mathbf{s x}}$ & $\mathbf{3 3 0 0}$ & 3000 & 1100 & $\mathbf{9 9 5 0}$ & 9840 & 180 & $\mathbf{8 8 6 0}$ & 9160 & 530 & $\mathbf{g ~ d m}^{-3}$ \\
\hline $\mathbf{K}_{\mathrm{sp}}$ & $\mathbf{5 3 0}$ & 460 & 220 & $\mathbf{6 2 8}$ & 595 & 25 & $\mathbf{6 5 3}$ & 630 & 19 & $\mathbf{g ~ ( g ~ d ) ~}^{-1}$ \\
\hline $\mathbf{q}_{\mathrm{pmax}}$ & $\mathbf{8 4 0}$ & 760 & 340 & $\mathbf{4 5 6 0}$ & 4310 & 180 & $\mathbf{3 7 2 0}$ & 3600 & 110 & $\mathbf{g ~ d m}^{-3}$ \\
\hline $\mathbf{Y}_{\mathbf{x} / \mathbf{s}}$ & $\mathbf{1 . 2 1}$ & 0.90 & 0.79 & $\mathbf{0 . 5 2}$ & 0.47 & 0.34 & $\mathbf{0 . 6 2}$ & 0.70 & 0.28 & - \\
\hline $\mathbf{Y}_{\mathbf{n} / \mathbf{s}}$ & $\mathbf{0 . 3 7}$ & 0.72 & 0.46 & $\mathbf{0 . 3 6 5 0}$ & 0.3638 & 0.0007 & $\mathbf{0 . 3 7 4 0}$ & 0.3748 & 0.0007 & - \\
\hline
\end{tabular}

TABLE 2c

Best fit Aiba model parameters for May 2017, July 2017, and October 2017, with averages $(\mu)$ and standard deviations $(\sigma)$.

\begin{tabular}{|r|c|c|c|c|c|c|c|c|c|l|}
\hline & \multicolumn{3}{|c|}{ May-17 } & \multicolumn{3}{|c|}{ Jul-17 } & \multicolumn{3}{|c|}{ Oct-17 } \\
\hline Parameter & Best & $\boldsymbol{\mu}$ & $\boldsymbol{\sigma}$ & $\mathbf{B e s t}$ & $\boldsymbol{\mu}$ & $\boldsymbol{\sigma}$ & $\mathbf{B e s t}$ & $\boldsymbol{\mu}$ & $\boldsymbol{\sigma}$ & units \\
\hline $\boldsymbol{\mu}_{\max }$ & $\mathbf{0 . 1 5}$ & 0.15 & 0.01 & $\mathbf{0 . 4 3}$ & 0.14 & 0.04 & $\mathbf{0 . 3 9}$ & 0.41 & 0.01 & $\mathbf{d}^{\mathbf{1}}$ \\
\hline $\mathbf{K}_{\mathbf{s x}}$ & $\mathbf{9 7 5 0}$ & 9740 & 470 & $\mathbf{9 4 5 0}$ & 9890 & 870 & $\mathbf{9 1 3 0}$ & 9170 & 300 & $\mathbf{g ~ d m}^{-3}$ \\
\hline $\mathbf{K}_{\text {sp }}$ & $\mathbf{8 5 0}$ & 1040 & 120 & $\mathbf{1 3 1 . 4}$ & 1.9 & 5.5 & $\mathbf{3 1 7}$ & 304 & 28 & $\mathbf{g ~ ( g ~ d ) ~}^{-1}$ \\
\hline $\mathbf{q}_{\text {pmax }}$ & $\mathbf{3 9 5 0}$ & 4000 & 110 & $\mathbf{3 7 3 0}$ & 4880 & 470 & $\mathbf{3 7 0 0}$ & 3480 & 140 & $\mathbf{g ~ d m}^{-3}$ \\
\hline $\mathbf{Y}_{\mathbf{x} / \mathbf{s}}$ & $\mathbf{0 . 0 5 3}$ & 0.031 & 0.016 & $\mathbf{0 . 0 3}$ & 0.34 & 0.47 & $\mathbf{1 . 2}$ & 1.5 & 0.4 & - \\
\hline $\mathbf{Y}_{\mathrm{p} / \mathbf{s}}$ & $\mathbf{0 . 3 7 8}$ & 0.374 & 0.005 & $\mathbf{0 . 3 8}$ & 0.28 & 0.05 & $\mathbf{0 . 3 8 4}$ & 0.382 & 0.002 & - \\
\hline $\mathbf{K}_{\text {ix }}$ & $\mathbf{1 5 . 1}$ & 14.6 & 4.3 & $\mathbf{2 0 . 2}$ & 1.4 & 1.3 & $\mathbf{1 2 . 5}$ & 7.3 & 2.8 & $\mathbf{g ~ d m}^{-3}$ \\
\hline $\mathbf{K}_{\text {in }}$ & $\mathbf{0 . 0 3 5}$ & 0.030 & 0.003 & $\mathbf{0 . 0 3 9}$ & 0.022 & 0.007 & $\mathbf{0 . 0 1 9}$ & 0.017 & 0.002 & $\mathbf{g ~ d m}^{-3}$ \\
\hline
\end{tabular}

TABLE 2d

Best fit Hinshelwood model parameters for May 2017, July 2017, and October 2017, with averages $(\mu)$ and standard deviations $(\sigma)$.

\begin{tabular}{|c|c|c|c|c|c|c|c|c|c|c|}
\hline \multirow[b]{2}{*}{ Parameter } & \multicolumn{3}{|c|}{ May-17 } & \multicolumn{3}{|c|}{ Jul-17 } & \multicolumn{3}{|c|}{ Oct-17 } & \multirow[b]{2}{*}{ units } \\
\hline & Best & $\mu$ & $\sigma$ & Best & $\mu$ & $\sigma$ & Best & $\mu$ & $\sigma$ & \\
\hline$\mu_{\max }$ & 0.18 & 0.16 & 0.02 & 0.42 & 0.41 & 0.01 & 0.40 & 0.42 & 0.01 & $d^{-1}$ \\
\hline $\mathbf{K}_{\mathrm{sx}}$ & 10860 & 10290 & 920 & 8848 & 8932 & 95 & 9340 & 9940 & 920 & $\mathrm{~g} \mathrm{dm}^{-3}$ \\
\hline $\mathbf{K}_{\mathrm{sp}}$ & 1040 & 1134 & 52 & 200 & 209 & 5 & 381 & 395 & 12 & $g(g ~ d)^{-1}$ \\
\hline $\mathbf{q}_{\mathrm{pmax}}$ & 3710 & 3960 & 140 & 3350 & 3460 & 60 & 3420 & 3539 & 79 & $\mathrm{~g} \mathrm{dm}^{-3}$ \\
\hline $\mathbf{Y}_{\mathbf{x} / \mathbf{s}}$ & 0.13 & 0.15 & 0.10 & 0.95 & 0.74 & 0.32 & 0.92 & 1.04 & 0.27 & - \\
\hline $\mathbf{Y}_{\mathrm{p} / \mathrm{s}}$ & 0.390 & 0.389 & 0.001 & 0.38 & 0.37 & 0.02 & 0.384 & 0.384 & 0.001 & - \\
\hline $\mathbf{K}_{\mathrm{ix}}$ & 5.0 & 5.5 & 0.4 & 7.5 & 7.7 & 0.3 & 2.0 & 2.4 & 0.3 & $\mathrm{~g} \mathrm{dm}^{-3}$ \\
\hline $\mathbf{K}_{\mathrm{ip}}$ & $\begin{array}{l}7.9 \mathrm{x} \\
10^{-7} \\
\end{array}$ & $\begin{array}{l}2.1 \mathrm{x} \\
10^{-5}\end{array}$ & $\begin{array}{l}1.9 \mathrm{x} \\
10^{-5}\end{array}$ & $\begin{array}{l}3.1 \mathrm{x} \\
10^{-6} \\
\end{array}$ & $\begin{array}{l}2.7 \mathrm{x} \\
10^{-6} \\
\end{array}$ & $\begin{array}{l}1.1 \mathrm{x} \\
10^{-6}\end{array}$ & 0.0022 & 0.0005 & 0.0009 & $\mathrm{~g} \mathrm{dm}^{-3}$ \\
\hline
\end{tabular}

TABLE 3

Data Model Comparison for May, July, and October, 2017. No. $=$ Number of Parameters, Cost $=$ Cost Function and RSS $=$ Modified RSS

\begin{tabular}{|l|c|c|c|c|c|c|c|c|c|c|}
\hline & & \multicolumn{3}{|c|}{ May, N $=1320$} & \multicolumn{3}{c|}{ July, N=507 } & \multicolumn{3}{c|}{ October, N $=575$} \\
\hline Model & No. & Cost & RSS & AIC & Cost & RSS & AIC & Cost & RSS & AIC \\
\hline Monod & 6 & 383 & 0.30 & 9.5 & 130 & 0.26 & 9.3 & 92 & 0.16 & 8.3 \\
\hline Tessier & 6 & 376 & 0.28 & 9.5 & 127 & 0.25 & 9.2 & 84 & 0.15 & 8.2 \\
\hline Aiba & 8 & 275 & 0.21 & 12.9 & 63 & 0.12 & 11.8 & 41 & 0.071 & 10.7 \\
\hline $\begin{array}{l}\text { Hinshel- } \\
\text { wood }\end{array}$ & 8 & 196 & 0.15 & 12.2 & 30 & 0.059 & 10.3 & 31 & 0.054 & 10.2 \\
\hline
\end{tabular}


further reinforced when they see the process components physically during the construction of control block diagrams for the brewing process, like the one in Figure 4. Block diagrams are a struggle for many students, and pairing their physical observations with the diagrams is a valuable tool. In future controls analyses and discussions, the collection of data to be able to determine the actual transfer functions, " $G$," associated with the individual segments would even further enhance student understanding of process control. Exploring and describing the consequences of poor (or no) control on a process's quality is a watershed in students' understanding of process engineering. The ability to provide smooth and rapid responses to system changes is just as important as being flexible enough to handle a broad range of conditions and disturbances. Exploiting student-generated models in computational software allows educators to demonstrate and adequately discuss these important tradeoffs. After comparison of process data with modeled data, students gain ap-

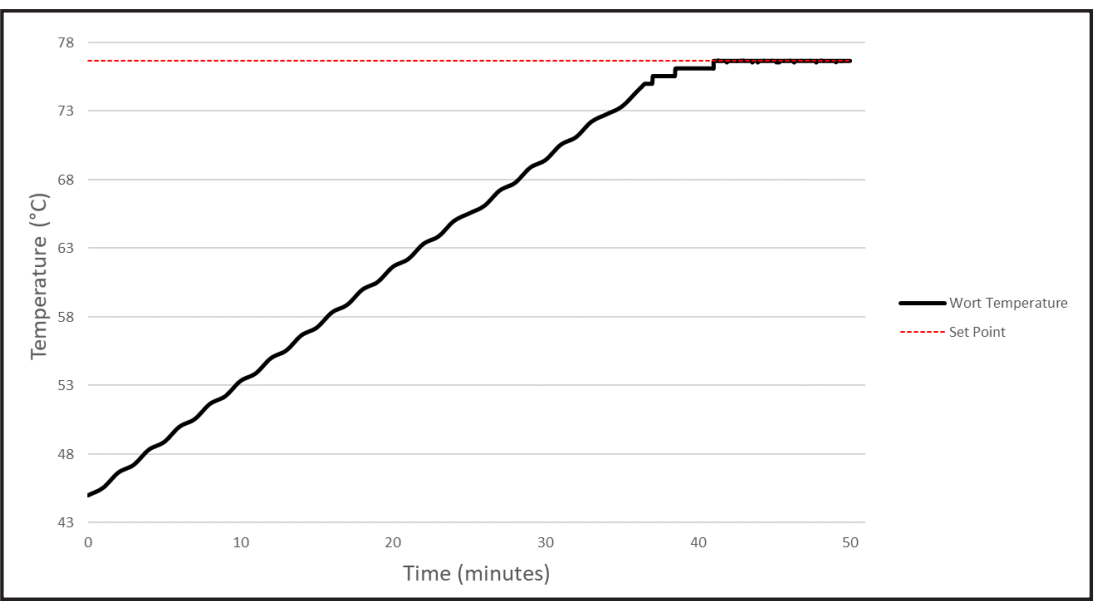

Figure 3. Temperature control of the wort tank using PID. Strict adherence to the set point with no oscillation is a great demonstration of the benefits of derivative control.

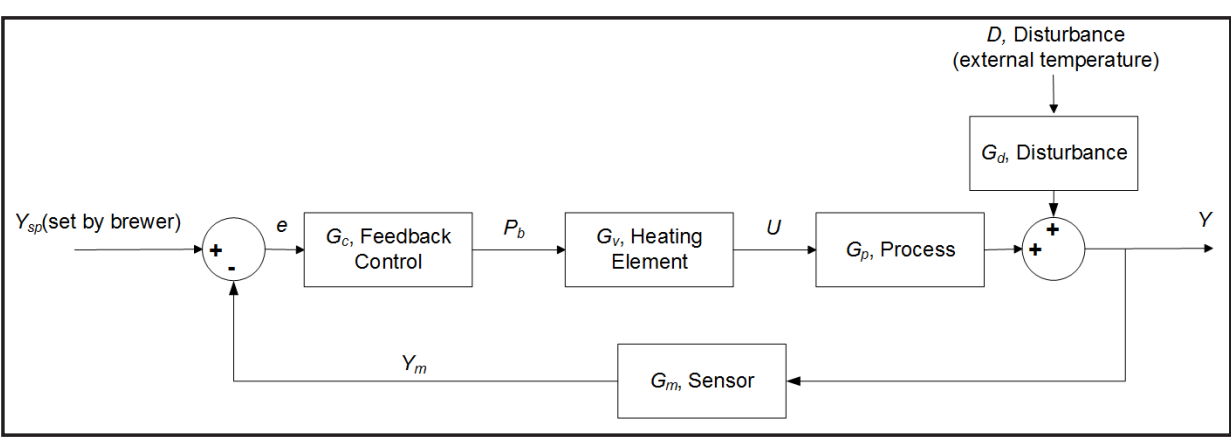

Figure 4. Block diagram for the temperature control law associated with the wort tank. Specifically, Ysp is the temperature set point; $e$ is the difference between the set point and the actual temperature, $\mathrm{Ym}$; and $\mathrm{Pb}$ is the electricity sent to the heating element (if required) to produce the heat, $U$, required to change the temperature of the wort (the process). All of the " $G$ " terms represent the transfer functions of the individual control loop elements.
TABLE 4

Comparison of Hydrometer and GC-MS measurements of EtOH (\%)

\begin{tabular}{|c|c|c|c|c|c|c|c|}
\hline No. & Date & $\begin{array}{l}\text { Time } \\
\text { (hrs) }\end{array}$ & $\begin{array}{c}\text { Running } \\
\text { Time } \\
\text { (min) }\end{array}$ & $\begin{array}{l}\text { Hydrometer } \\
\text { specific } \\
\text { gravity }\end{array}$ & $\begin{array}{c}\text { Hydrometer } \\
\text { ABV }(\%)^{*}\end{array}$ & $\begin{array}{l}\text { glucose } \\
\text { conc. } \\
\text { (mol/L) }\end{array}$ & $\begin{array}{c}\text { GC-MS } \\
\text { ABV(\%) }\end{array}$ \\
\hline 1 & 2-Oct & 1612 & 0 & & 0 & - & - \\
\hline 2 & 3-Oct & 740 & 928 & 1.063 & 0.3 & 0.93618 & $0.3 \pm 0.2$ \\
\hline 3 & 4-Oct & 910 & 2458 & 1.037 & 3.7 & 0.54982 & $3.6 \pm 0.2$ \\
\hline 4 & & 1500 & 2808 & 1.034 & 4.1 & 0.50524 & $3.8 \pm 0.2$ \\
\hline 5 & 5-Oct & 845 & 3873 & 1.022 & 5.7 & 0.32692 & $5.3 \pm 0.2$ \\
\hline 6 & & 1500 & 4248 & 1.02 & 5.9 & 0.2972 & - \\
\hline 7 & 6-Oct & 1330 & 5598 & 1.016 & 6.5 & 0.23776 & $7.0 \pm 0.2$ \\
\hline 8 & 8-Oct & 1000 & 8268 & 1.010 & 7.2 & 0.1486 & - \\
\hline
\end{tabular}

preciation for the importance of accurate modeling prior to control law implementation. ${ }^{[9]}$ A basic "PID control model" can be constructed to replicate the action of the wort heating element, where the cadets can use the following equations to analyze the model of $\mathrm{u}(\mathrm{t})$ and $\mathrm{e}(\mathrm{t})$, the controller effort and error signal, and incorporate an energy balance:

$$
\begin{gathered}
u(t)=K_{P}\left(e(t)+\frac{1}{\tau_{1}} \int_{0}^{t} e(t) d t+\frac{1}{\tau_{D}} \frac{d e(t)}{d t}\right) \\
e(t)=T(t)-T_{\text {set }}
\end{gathered}
$$

where $K_{p}$ is the gain, $\tau_{I}$ is the integral constant and $\tau_{D}$ is the derivative constant. Students, and arguably some operators in industry, typically are challenged by calculating and implementing tuning parameters in controllers. Having the ability to adjust tuning parameters using widely accepted methods provides the perfect environment for students to "see" the adjustments take effect. The energy balance for the on/off temperature controller is shown below:

$$
\mathrm{V}_{\text {tank }} \rho_{\text {wort }} \mathrm{C}_{\mathrm{p}-\text { wort }} \frac{\mathrm{dT}}{\mathrm{dt}}=\dot{\mathrm{Q}}
$$

where $\rho_{\text {wort }}$ is the density of the wort, $C_{p_{-} \text {wort }}$ is the heat capacity of the wort, $V_{\text {tank }}$ is the tank volume, the quantity $\mathrm{dT} / \mathrm{dt}$ is the time derivative of the temperature and $Q$ is the heat flow rate of the heater. With Eqs. 11-13, the cadets can design a basic controller and 
adjust the control parameters $K_{p}, \tau_{I}$, and $\tau_{D}$ until the control effort reaches zero with minimal oscillation, overshoot, or offset. In addition, the cadets can verify the appropriate heat was applied by analysis of the energy balance equation. ${ }^{[19]}$

\section{HEAT AND MASS TRANSFER ANALYSIS}

The cooling of the boiled wort to an appropriate temperature for fermentation provides data for cadets to conduct both energy balances and heat exchanger design calculations. Measuring the inlet and outlet temperatures of both the wort and the cooling water, as well as the volumetric flow rates, allows cadets to conduct an energy balance around the heat exchanger. Cadets gain experience in measuring quantities that, for the most part, have been abstract 'givens' in their academic careers. This provides great opportunities for demonstrating everything from a known-volume (sanitized) bucket and stop watch to more accurate rotameters. Discussions and calculations with uncertainties and error propagation necessarily follow as well. These calculations are directly applicable to the classroom or the lab in our Heat and Mass Transfer course, $\mathrm{CH} 485$. In addition, the cadets conduct similar analysis in the Chemical Engineering Lab course, CH459, using a single effect evaporator, also performing mass and energy balances and calculating the heat transfer coefficient.

After completing an energy balance, cadets use the data they have collected to analyze the plate heat exchanger used by the brewing crew. The wort is run in a single continuous flow through the plate heat exchanger, counter-current to the coolant water from a bench sink in the brewing room. From the flows and temperatures, they are required to calculate the overall heat transfer coefficient, $U a$, for the heat exchanger, using Eqs. 14 and 15.

$$
\mathrm{Q}_{\text {load }}=\mathrm{Ua} \Delta \mathrm{T}_{\mathrm{LM}}
$$

where $\Delta T_{L M}$ is the log mean temperature difference for countercurrent flow, defined as

$$
\Delta T_{\text {LM }}=\frac{\left(T_{\text {cool_Feed }}-T_{\text {wort_exit }}\right)-\left(T_{\text {cool_exit }}-T_{\text {wort_Feed }}\right)}{\ln \left[\frac{T_{\text {cool_Feed }}-T_{\text {wort exit }}}{T_{\text {cool exit }}-T_{\text {wort Feed }}}\right]}
$$

where we define the parameters as follows:

$T_{\text {cool_Feed }}$ is the coolant (utility) fluid feed temperature

$T_{\text {cool_exit }}$ is the temperature of the coolant at the exit of the heat exchanger

$T_{\text {wort_Feed }}$ is the feed temperature of the wort (process fluid)

$T_{\text {wortexit }}$ is the temperature of the wort at the exit of the heat exchanger.

$$
\mathrm{Q}_{\text {load }}=\dot{\mathrm{m}}_{\mathrm{C}_{\text {p_wort }}} \Delta \mathrm{T}_{\text {wort }}
$$

where $Q_{\text {load }}$ is the heat load for the heat exchanger, $\dot{m}$ is the mass flow rate of the wort, $\hat{C}_{p_{-} \text {wort }}$ is the average specific heat capacity of the wort, and $\Delta T_{\text {wort }}^{p_{-} \text {wort }}$ is the change in temperature of the wort as it passes through the heat exchanger.

Because the cooling fluid is simply tap water from the bench sink, there is no control over the inlet temperature and only nominal control over the coolant flow rate. However, the wort flow can be varied using a pump, taking between 2 and 10 minutes to circulate a single fermenter of about 15 gallons. The equipment available did not allow immediate temperature feedback to demonstrate the initial time dependency of both the wort feed (slowly cooling from initial boiling) and exit temperatures. Though providing potential for future data, discussion, and modeling, the flow rates were assumed to be sufficient to allow the heat exchanger to reach steady state, making equations appropriate for modeling.

The lack of control of the cooling water flow rates and temperatures results in the data taken from every batch being different, with the most noticeable contrast between summer and winter brews where the inlet temperature can vary by several degrees. The varying data allows cadets, over time, to develop an accurate picture of how the heat transfer coefficient varies (or remains constant) as the conditions change. This variation is a great demonstration of why tabulated heat exchange coefficients ${ }^{[8]}$ are general estimates, at best, and confirmation through experimental data is almost always required. Finally, cadets are able to model the heat exchanger within the CHEMCAD modeling software. They are able to develop their skills with the simulation via several mechanisms. Wort is not one of the materials routinely found in the data library of the code, so cadets either have to choose a simulated fluid (water is usually a starting point for novice users), calculate a representative sugar content, or define their own material. They are able to compare their energy balance with that calculated from the actual 
flow data they take. ${ }^{[8]}$ Figure 5 shows a CHEMCAD heat exchanger flowchart, while Tables 5 and 6 show the stream and equipment boxes from the CHEMCAD solution, which is in close agreement with our data from the analysis of the wort heat exchanger.

Modifying equations 14 and 16, as shown below, we calculate the product $U a$

$$
\begin{gathered}
\left(\rho \mathrm{C}_{\mathrm{p}} \Delta \mathrm{T} \dot{\mathrm{V}}\right)_{\text {cooling water }}=\left(\rho \mathrm{C}_{\mathrm{p}} \Delta \mathrm{T} \dot{\mathrm{V}}\right)_{\text {wort }} \\
\left(\rho \mathrm{C}_{\mathrm{p}} \Delta \mathrm{T} \dot{\mathrm{V}}\right)_{\text {cooling water }}=\mathrm{Ua} \Delta \mathrm{T}_{\mathrm{LM}}
\end{gathered}
$$

where $\rho$ is the density of the water and wort respectively ( 1.0 and $1.06 \mathrm{~g} / \mathrm{mL}$ ); $C_{p}$ is the heat capacity assumed to be the same for both water and wort; $\Delta \mathrm{T}$ is the temperature difference between the inlet and outlet; and $\dot{\mathrm{V}}$ is the volumetric flow rate; $U$ is the overall heat transfer coefficient; $a$ is the surface area; and $\Delta \mathrm{T}_{\mathrm{LM}}$ is the $\log$ mean temperature difference for countercurrent flow.

For a verification of the CHEMCAD simulation, we turn to the Therminator Performance Data shown in the Therminator Owners Manual.

${ }^{[20]}$ The performance data figure of the manual uses the following parameters: wort specific gravity of 1.04; wort outlet temperature of $68^{\circ} \mathrm{F}\left(20^{\circ} \mathrm{C}\right)$; and wort inlet temperature of $212^{\circ} \mathrm{F}\left(100^{\circ} \mathrm{C}\right)$. Choosing a cooling water inlet temperature of $60^{\circ} \mathrm{F}\left(15.6^{\circ} \mathrm{C}\right)$ and cooling water flow rate of 2.5 gallons per minute, the required wort flow rate is approximately 1.25 gallons per minute. These are the values (with converted units) used in the simulation demonstrated in Tables 5 and 6. Although a value of $U a$ is not available from the Owner's Manual, the charted flow values match very nearly to those calculated by CHEMCAD. In the future, careful measurement of inlet and outlet temperatures will allow more direct calculation of $U a$ and comparisons to the manufacturer's performance data.
TABLE 5

An example CHEMCAD stream report showing the properties of the flow streams from Figure 5. The data can be used in energy balance calculations and compared to measured values.

\begin{tabular}{|l|l|l|l|l|}
\hline Stream No & 1 & 2 & 3 & 4 \\
\hline Name & Wort Feed & Wort Out & Water feed & Water Out \\
\hline-- Overall- & & & & \\
\hline Temp C & 99.9000 & 20.0000 & 15.5600 & 57.4324 \\
\hline Enth MJ/sec & -1.3011 & -1.3291 & -2.5437 & -2.5157 \\
\hline Mass flow kg/s & 0.0837 & 0.0837 & 0.1600 & 0.1600 \\
\hline Std liq cc/sec & 83.7001 & 83.7011 & 160.0002 & 160.0002 \\
\hline-- Liquid only-- & & & & \\
\hline Mass flow kg/s & 0.0837 & 0.0837 & 0.1600 & 0.1600 \\
\hline \hline
\end{tabular}

\section{PROCESS ECONOMICS AND PRODUCT ENGINEERING}

Data for analysis of the profitability (or lack thereof) of our brewing process is shown in Tables 7 to 9 . Based on a careful analysis of the data shown in Table 7, we can produce a maximum of 16 gallons of Kicking Mule per batch, correlating to 128 pints. At $\$ 2.50 /$ pint, the going rate of a pint of Kicking Mule, we earn $\$ 320.00$ per batch of Kicking Mule. By subtracting off the cost of a batch of Kicking Mule (\$20.00 for yeast, $\$ 40.00$ for grain and additives, and $\$ 20.00$ for hops), our profit per batch is roughly $\$ 240.00$.

Considering the overall investment in the equipment necessary for the operation (described in Figure 2), we see the total initial cost is $\$ 6150.00$. With a profit per batch of $\$ 280.00$ it will take approximately 26 batches of Kicking Mule to recoup the cost of the initial investment.

As an extracurricular activity, some standard economic expenses are not

\begin{tabular}{|c|c|}
\hline \multicolumn{2}{|c|}{$\begin{array}{c}\text { TABLE } 8 \\
\text { Cost per Batch }\end{array}$} \\
\hline Ingredient & Cost (\$) \\
\hline Yeast & 20.00 \\
\hline Hops & 20.00 \\
\hline Bulk Grain and Additives & $20.00-40.00$ \\
\hline $\mathrm{CO}_{2}$ & - \\
\hline Total Spent (\$) & 80.00 \\
\hline Total Brought in (\$) & 320.00 \\
\hline Profit (\$) per Batch & 240.00 \\
\hline
\end{tabular}
evaluated in this process. Most nota-
Chemical Engineering Education

\begin{tabular}{|c|c|}
\hline \multicolumn{2}{|c|}{ TABLE 9 } \\
Long Term Investment Cost \\
\hline \multicolumn{2}{|c|}{ Long Term Investment } \\
\hline Equipment & Cost (\$) \\
\hline Heat Exchanger & 200.00 \\
\hline Refrigerator & 150.00 \\
\hline Grinder & 100.00 \\
\hline Batch Reactor & 1000.00 \\
\hline EHERMs & 4700.00 \\
\hline Total: & 6150.00 \\
\hline
\end{tabular}

\begin{tabular}{|l|c|} 
TABLE 6 \\
A sample equipment table from CHEMCAD showing the \\
heat exchange coefficient, U, and heat exchanger area, a, \\
calculated by the simulation for the properties specified.
\end{tabular}

Pints \& (\$) of Kicking Mule Produced per batch

\begin{tabular}{|c|c|c|c|}
\hline Gallons & Pints & Cost (\$)/pint & Total (\$)/ batch \\
\hline 16 & 128 & 2.50 & 320.00 \\
\hline
\end{tabular}

Chemical Engineering Education 
bly, labor costs, traditionally a significant portion of operational costs, are not included in this basic analysis. Other considerations, including estimated values of depreciation, equipment replacement or maintenance timelines and costs, utility costs, and even interest rates can be used for more complex and long-term analyses of the sustainability of the process. When viewed as a pilot plant, these more detailed economic concerns can be analyzed within the context of scaling this batch system to a more industrial scale where such considerations are critical and cannot be assumed as negligible.

With respect to quality control, each recipe is diligently recorded, and notes taken about the quality of the flavor, coloring, alcohol content etc. for future Kicking Mule batch reproduction. Typically, the overall batch quality is determined qualitatively and quantitatively through measurements of density (then converted to alcohol content), coloring and informal surveys from the point of sale.

\section{CONCLUSION}

Fundamentally, the beer brewing operations of the Kicking Mule Brewing Co. allow the members of the club to put

\section{REFERENCES}

1. Cerretani CC, Kelkile E and Landry A (2017) Learning by brewing: beer production experiments in the chemical engineering laboratory, Chem. Engr. Ed., 51(4): 205-215. http://journals.fcla.edu/cee/article/ view/104871

2. Nielsen RP, Sorensen J, Simonsen KM, Madsen H, Muff J, Strandgaard M and Sogaard E (2016) Brewing as a comprehensive learning platform in chemical engineering, J. Chem. Ed. 93, 1549-1555. DOI:10.1021/ acs.jchemed.5b00994

3. Hooker PD, Deutschman, W and Avery B (2014) The biology and chemistry of brewing: an interdisciplinary course, J. Chem. Ed. 91, 336-339. DOI: 10.1021/ed400523m

4. Korolija JN, Plavsic J, Marinkovic D and Mandic L (2012) Beer as a teaching aid in the classroom and laboratory, J.Chem.Ed. 89, 605-609. DOI: $10.1021 / \mathrm{ed} 200187 \mathrm{c}$

5. Gillespie B (2010) Brewing beer in the laboratory: grain amylases and yeast's sweet tooth, J. Chem. Ed. 87(11): 1244-1247. DOI: 10.1021/ ed $100442 b$

6. Fix G (1999) Principles of Brewing Science. Brewers Publications, Boulder, $\mathrm{CO}$.

7. Fogler SH (2006) Elements of Chemical Reaction Engineering, 4th ed. Prentice Hall, Upper Saddle River, NJ.

8. Russell TW, Robinson A and Wagner N (2008) Mass and Heat Transfer, Cambridge University Press, New York, NY.

9. Seborg, DE, Edgar T, Mellichamp D and Doyle F (2017), Process Dynamics and Control, 4th Ed. Wiley, Chennai, India.

10. Felder RM, Rousseau R and Bullard L (2016) Elementary Principles of Chemical Processes, 4th ed. John Wiley \& Sons, Hoboken, NJ.

11. Seader JD, Henley E and Roper D (2011) Separation Process Principles, Chemical Biochemical Operations, 3rd ed. John Wiley \& Sons, Hoboken, NJ.

12. Armstrong MJ, Wagner N and Beris A (2017) An adaptive parallel tempering method for the dynamic data-driven parameter estimation of nonlinear models, AIChE J. 63(6): 1937-1958. https://doi.org/10.1002/ into practice the chemical engineering principles they have learned (or will learn) through their classroom and laboratory experiences. Their learning is enhanced through real-world measurements, data analysis, uncertainty propagation, and, ultimately, the production of a useable, saleable, product that meets the needs (wants) of a client. In the future, there is the potential for even more exploration of various chemical engineering principles, including jacket heat exchangers, batch chemical reactors, the economic and profitability analysis, etc. It should also be noted that the data generated in the execution of a single batch of Kicking Mule can be used in the context of the reactor design, controls and heat transfer chemical engineering electives. The focus has been, and will continue to be, providing an excellent, but continually improving, undergraduate chemical engineering education.

\section{ACKNOWLEDGEMENTS}

The authors acknowledge the support and funding assistance from the U.S. Army, and the Department of Chemistry and Life Science, United States Military Academy. The views expressed herein are those of the authors and do not reflect the position of the United States Military Academy, the Department of the Army, or the Department of Defense.

aic. 15577

13. Parcunev I, Vessela N, Kostov G, Yanakiev Y, Popova Z, Kaneva M and Ignatov I (2012) Modeling of Alcohol Fermentation in Brewing - Some Practical Approaches. Proceedings 26th European Conf. on Modeling and Simulation. Koblenz, Germany. DOI: 10.7148/2012-0434-0440

14. Kostov G, Popova S, Gochev V, Koprinkova-Hristova P, Angelov M and Georgieva A (2012) Modeling of Batch Alcohol Fermentation with Free and Immobilized Yeasts Saccharomyces Cerevisiae 46 EVD. Biotechnology and Biotechnological Equipment 26 (3), 3021-3030 https://doi.org/10.5504/BBEQ.2012.0025

15. Vassilev S, Naydenova V, Badova M, Iliev V, Kaneva M and Kostov G (2013) Modeling of Alcohol Fermentation in Brewing Comparative Assessment of Flavor Profile of Beers Produced with Free and Immobilized Cells. Proceedings 27th European Conf. on Modeling and Simulation. Alesund, Norway DOI: 10.7148/2013-0415

16. Liu D, Xu L, Xiong W, Zhang H, Lin C, Jiang L and B. Xu B (2014) Fermentation Process Modeling with Levenberg-Marquardt Algorithm, and Runge-Kutta Method on Ethanol Production by Saccharaomyces Cerevisiae. Mathematical Problems in Engineering 2014, 1-10 http:/ dx.doi.org/10.1155/2014/289492

17. Andres-Toro B, Giron-Sierra J, Lopez-Orozco J, Fernandez-Conde C, OPeinado J and Garcia-Ochoa F (1998) A kinetic model for beer production under industrial operational conditions, Mathematics and Computers in Simulation, 18, 65-74 https://doi.org/10.1016/S03784754(98)00147-5

18. Aikaie, $\mathrm{H}(1974)$ A new look at the statistical model identification. IEEE Transactions on Automatic Control, 19(6): 716-723. DOI: 10.1109/ TAC.1974.1100705

19. Scheer FM (n.d.) Thermal Process Engineering for Brewers, Basics in Theory and Practice, Fred M Scheer Brewing Process and Technology, Krones Inc.

20. Blichmann Engineering Therminator Owners Manual-V8. Blichmann Engineering, LLC (2008) $\square$ 